\title{
Insights in Fault Flow Behaviour from Onshore Nigeria Petroleum System Modelling
}

\author{
Marie-Noëlle Woillez ${ }^{1}{ }^{*}$, Christine Souque ${ }^{1}$, Jean-Luc Rudkiewicz ${ }^{1}$, Françoise Willien ${ }^{1}$ and \\ Tristan Cornu ${ }^{2}$ \\ 1 IFP Energies nouvelles, 1-4, avenue de Bois-Préau, 92852 Rueil-Malmaison Cedex - France \\ 2 Total Exploration Production Research and Development, avenue Larribeau, 64000 Pau - France \\ marie-noelle.woillez@ifpen.fr \\ *Corresponding author
}

\begin{abstract}
Faults are complex geological features acting either as permeability barrier, baffle or drain to fluid flow in sedimentary basins. Their role can be crucial for over-pressure building and hydrocarbon migration, therefore they have to be properly integrated in basin modelling. The ArcTem basin simulator included in the TemisFlow software has been specifically designed to improve the modelling of faulted geological settings and to get a numerical representation of fault zones closer to the geological description. Here we present new developments in the simulator to compute fault properties through time as a function of available geological parameters, for single-phase $2 D$ simulations. We have used this new prototype to model pressure evolution on a siliciclastic $2 D$ section located onshore in the Niger Delta. The section is crossed by several normal growth faults which subdivide the basin into several sedimentary units and appear to be lateral limits of strong over-pressured zones. Faults are also thought to play a crucial role in hydrocarbons migration from the deep source rocks to shallow reservoirs. We automatically compute the Shale Gouge Ratio (SGR) along the fault planes through time, as well as the fault displacement velocity. The fault core permeability is then computed as a function of the SGR, including threshold values to account for shale smear formation. Longitudinal fault fluid flow is enhanced during periods of high fault slip velocity. The method allows us to simulate both along-fault drainages during the basin history as well as overpressure building at present-day. The simulated pressures are at first order within the range of observed pressures we had at our disposal.
\end{abstract}

\section{INTRODUCTION}

Basin modelling is used in exploration to evaluate the petroleum potential of the basin and to assess the distribution of fluid overpressures. Based on a geological model, it allows the assessment of the burial history, the thermal history leading to the maturity of the source rocks, petroleum expulsion, migration and trapping (Rudkiewicz et al., 2000). Fluid flow pathways and fluid pressure evolution are obtained considering the reduction of porosity with effective pressure (burial and fluid pressure) for different lithologies, the associated evolution of permeability, and the input of fluids in the system through diagenesis and petroleum generation (Schneider et al., 2000; Caillet and Batiot, 2003; Peters et al., 2008). Natural diffuse fracturing and its impact on permeability is integrated, while faults and their impact on fluid flow can currently be added only as a specific lithology in the model (Caillet and Batiot, 2003) or as transmissibility multipliers (Manzocchi et al., 1999).

The aim of this paper is to model the overpressure for a section located onshore in Nigeria, with an improved model of normal syn-sedimentary faults, so that some new insights on fault properties through time can be inferred. We focus on a siliciclastic geological environment, with active synsedimentary faults. 
Faults are complex geological features that can act either as permeability barrier, baffle or drain to fluid flow in sedimentary basins (Grauls and Baleix, 1994; Wibberley et al., 2008; Manzocchi et al., 2010; Wibberley et al., 2016). Their role can be crucial in over-pressure building and for petroleum migration. Therefore, they have to be properly taken into account in basin modelling. Classically, geologists divide a fault into two main elements: the central fault core and the surrounding damage zone (Fredman et al., 2007).

The fault core corresponds to the most damaged part, where most of the displacement is accommodated. It is composed of highly crushed and mixed material from the host rocks, whose permeability can be empirically related to its shale content (Manzocchi et al., 1999; Sperrevik et al., 2002). In shale-rich settings, shaly layers can be dragged in the fault core and create a continuous (or discontinuous) shale smear with a very low permeability preventing across-fault fluid flow (Sperrevik et al., 2000; Schmatz et al., 2010).

The damage zone is the peripheral zone where the host rock is deformed but still recognizable. Depending on the lithology and stress field, different deformation structures may occur. In clean and porous sandstones deformation in the damage zone occurs by brittle faulting, producing deformation bands with or without cataclasis, depending on the burial depth (Aydin, 1977, 1978). They consist of thin zones (typically $1 \mathrm{~mm}-$ thick) of crushed and compacted quartz grains with a reduced permeability compared to the undeformed hostrock. The impact of deformation bands on permeability reduction might be further increased when the temperature-induced quartz cementation starts. Indeed, since grain fracturing enhances the specific surface and gives clean surfaces for mineral nucleation, cementation in the cataclastic zones formed during fault movement is expected to be more efficient than in the undeformed hostrock (Walderhaug, 1996; Lander and Walderhaug, 1999; Fisher et al., 2003; Lander et al., 2008). This process can dramatically decrease porosity and thus permeability creating efficient permeability barriers. Other geological contexts may lead to permeability increase in the damage zone, through micro and macro-fracturing (Caine et al., 1996; Lockner et al., 2009; Micarelli et al., 2006). This is the case when faulting occurs in clean sandstone with low porosity or in any over-consolidated lithology, i.e. whose porosity at a given effective stress is lower than the porosity expected according to the compaction law. Over-consolidation may be linked to uplift and erosion processes, but also to diagenetic cementation. Fractures opening have a major impact on fault fluid flow, creating a longitudinal fluid pathway as long as they remain open. However, quantifying permeability increase associated with fracturing remains a major challenge since data available in the literature are usually based on plug measurements and, therefore, only micro-fractures are taken into account (Lockner et al., 2009;
Mitchell and Faulkner, 2012). The duration of such a preferential fluid pathway depends on several parameters (lithology, stress field, overpressure, etc.) and is therefore also very difficult to predict. Acoustic wave attenuation data suggest, in non-sedimentary rocks, a quasi-instantaneous healing of the macroscopic fracturing at the basin time-scale (<100 ky) (Lockner et al., 2009; Vidale and Li, 2003). Yet significant fluid flow could occur on very short time-scales and even at basin scale, short episodes of important fluid flow cannot be neglected, especially if they occur periodically. For a lithology with a high shale content $(>40 \%)$ and no overconsolidation, deformation in the damage zone is accommodated through multiple faulting with shale smear and not through brittle fracturing (Childs et al., 2007).

The fault control on across and longitudinal fluid flow depends on the type of structures encountered in the fault core and the damage zone. A fault may be a barrier for across fluid flow but a longitudinal drain, or allow both across and longitudinal fault fluid flow, or allow across-fault flow but have no impact on longitudinal flow. Several combinations are possible, that may evolve through time. Therefore, modelling fault flow in petroleum system evaluation requires to know the fault characteristics (at least thickness and permeability) through time.

The current approach used in basin calculators to simulate the impacts of faults on fluid flow does not allow to distinguish the impact of fault core properties from the damage zone properties nor to handle easily their evolution in space and time. In order to improve basin modelling in faulted geological environments, an improved basin modelling software became available to handle faults, using unstructured meshes (ArcTem calculator, see Tunc et al., 2012; Faille et al., 2014). This allows to represent realistic geometries obtained from restored balanced cross-sections, and to have them evolving with faults as discrete planes on which the displacement and flow properties will evolve through time, in extensive as well as in compressive settings. These evolutive geometries and properties allow to properly describe the structural trap development and to evaluate the hydrocarbon column height and fluid pressures. In addition, fault properties should be computed through time by the calculator, in order to spare the user from implementing these properties manually, which can be highly timeconsuming. Here we present such a numerical tool that was developed at IFPEN and implemented in ArcTem and applied to a $2 \mathrm{D}$ section in the onshore Nigerian delta.

\section{FAULT MODEL IN BASIN MODELLING}

In this study, we used a new tool for basin modelling developed at IFPEN (TemisFlow software using the ArcTem calculator). Contrary to classical basin simulators, 


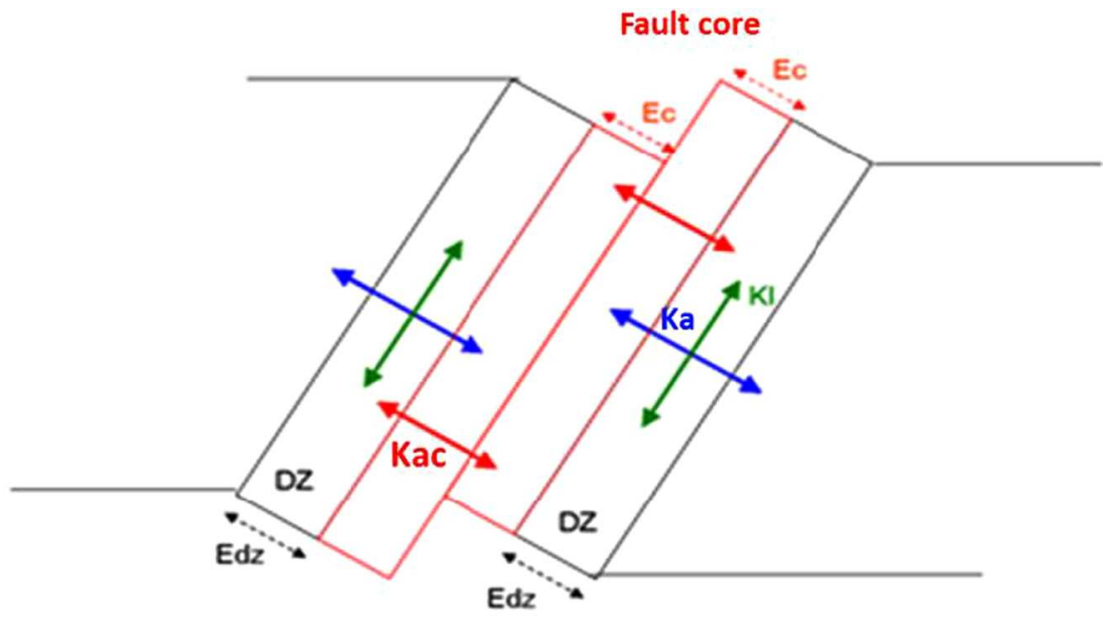

Kac : across permeability in the fault core

$\mathrm{Ka}$ : across permeability in the damage zone
$\mathrm{Kl}$ : longitudinal permeability in the damage zone DZ : damage zone

Figure 1

Schematic faults representation in ArcTem. The continuous arrows indicate the possible fluid flow across and along the fault. Kac, Ka and Kl can have different values on the footwall and the hanging wall. Ec and Edz: thickness of the fault core cell and damage zone respectively. All fault cells are implicit cells, which allows to avoid any re-meshing of the section depending on the chosen thicknesses. Therefore, these fault cells are not visible on figures showing the mesh of the section.

it does not require a structured mesh based on vertical pillars, and handles complex evolutive sections for sedimentary basins having experienced faulting episodes. The mesh is based on hexahedrons with degenerated grid cells on fault planes, which allows us to simulate realistic fault kinematic with layer displacements along a fault plane. The full description of the simulator principles for monophasic flow can be found in previous publications (Tunc et al., 2012; Faille et al., 2014), here we merely recall the way faults are handled.

The numerical representation of fault zones is getting closer to the geological description. They are taken into account as internal boundaries across which the mesh is nonmatching. For each face of a grid cell in contact with a fault surface, two implicit cells are defined (Fig. 1):

- The inner one, designed to simulate the impact of the fault core on fluid flow, has no volume and acts only as a transmissibility multiplier across the fault. The user has to define the thickness (Ec) and across permeability (Kac). Longitudinal fluid flow is not possible in this cell.

- The external one stands for the "damage zone". The user must define the thickness (Edz), across permeability (Ka) and longitudinal permeability $(\mathrm{Kl})$ as well as a threshold capillary pressure and relative permeability for multiphase flow (which we will not consider in this paper). This cell has a volume, and both longitudinal- and across-fault fluid flows can be simulated.
Using this approach we can simulate both across and longitudinal fluid flow and thus configurations where, for instance, the fault zone behaves as a lateral barrier but a longitudinal drain (Fig. 2). The user can also choose realistic values of damage zone and fault core thickness of only a few meters without any meshing issues that would arise from such a refinement in classical basin modelling in which faults are explicit grid cells (Caillet and Batiot, 2003). Indeed, since the ArcTem fault cells are implicit, no re-meshing is needed. All the thickness and permeability properties can evolve through time for each cell of the mesh.

\section{MODELING FAULTED GEOLOGICAL SETTINGS}

\subsection{Geological Context}

We have modelled a North-South 2D section located onshore in the Niger Delta, on the Gulf of Guinea on the West coast of Africa. Sedimentation began in Albian time, after the opening of the South Atlantic Ocean, with the deposit of Cretaceous units, covered by Maastrichtian calcareous shales. Then we find a thick sequence of Mobile Shales, grading upwards into marine shales including turbiditic reservoirs in the southern part and into interbedded deltaic sands and shales in the northern part. The whole section is overlain by the thick Benin sands formation, deposited during the last $10 \mathrm{Ma}$. The total thickness of the section can reach $12 \mathrm{~km}$ in the center of the basin. Several 

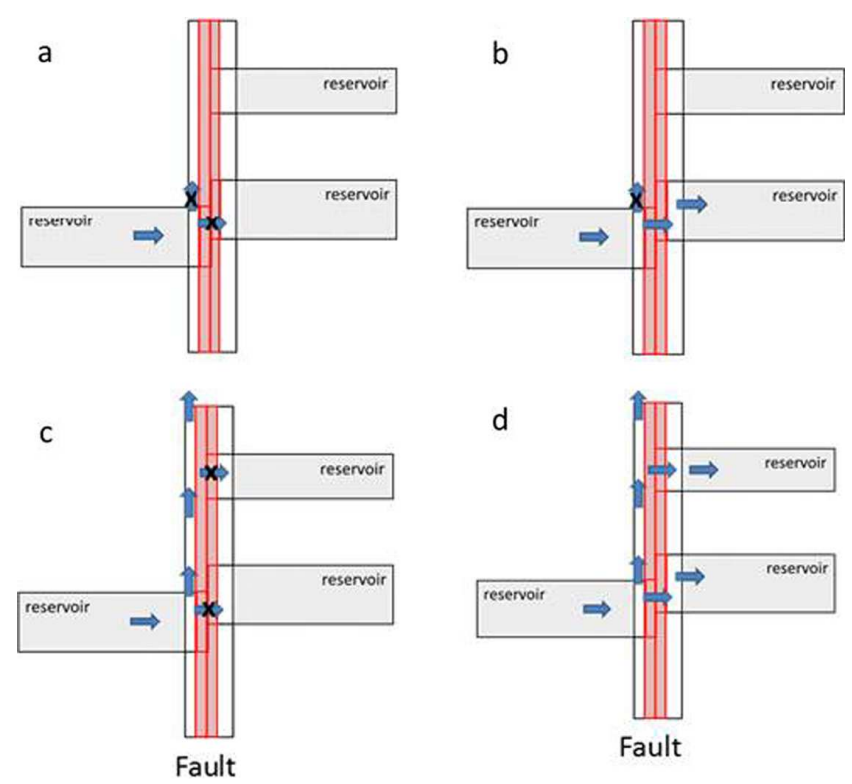

Figure 2

Examples of different fault fluid flows that can be simulated with ArcTem. Red cells $=$ fault core cells, blue arrow = fluid flow. (a) Impervious fault, no longitudinal or across-fault fluid flow. (b) No longitudinal fault fluid flow but across-fault flow is allowed. (c) No across-fault fluid flow, but longitudinal flow is allowed. (d) Longitudinal and across-fault fluid flows are allowed.

growth faults affect the deltaic sequence, probably triggered by the movement of the deep, over-pressured, ductile shales and slope instability further south. These growth faults subdivide the basin into several sedimentary units, each characterized by its own sand-shale distribution pattern. Pressure data from the wells penetrating the first km's of the section (maximum: $4.6 \mathrm{~km}$ ) show that the interbedded deltaic sands and shales are generally at hydrostatic pressure to a depth of $3500-4000 \mathrm{~m}$. Strong over-pressures are recorded in deeper layers and faults appear to be lateral limits of these different over-pressured zones.

The Niger Delta is a rich oil and gas province, with light waxy type oils and methane-rich gas (Caillet and Batiot, 2003). The source rocks are controversial, but the main sources are probably the Akata shales, which reach a high maturity level. Most of the petroleum already found in this area is located in shallow structural traps, either related to faults or to anticlines.

Fault properties appear to be crucial nonetheless to explain the strong over-pressure building on the section but also petroleum migration from the deep source rocks to the shallow reservoirs. Faults are thought to act as permeability barriers, except during syn-sedimentary activity. Our new developments to manage fault properties in the software (see Sect. 3) have not yet been made to handle migration simulations. Therefore, we will perform only pressure simulations and use the water pressure data at the wells to calibrate our fault model.

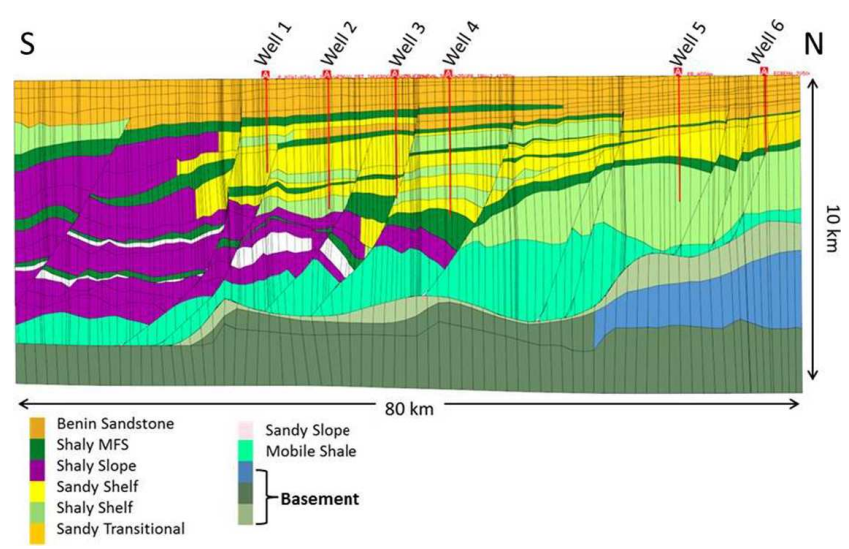

Figure 3

Geometry of the section with the lithology and location of the six wells with pressure data. The vertical scale is increased by 3. The fault network has been simplified.

\subsection{Workflow to Model a 2D Faulted Section: Application to the Niger Delta}

The workflow to perform a $2 \mathrm{D}$ basin simulation with ArcTem is as follows:

- Construct a geomodel at present-day, from seismic and well data.

- Structurally restore the model, calculate the evolution of fault displacement through time on each fault surface.

- Generate the 2D grid.

- Fill the grid with the relevant lithologies, from well data or from stratigraphic modelling.

- Forward basin simulation, here without organic matter maturation, nor oil and gas expulsion and migration.

- Calibrate to observations.

- Infer the flow properties of faults.

To construct the geomodel, we used 23 horizons from seismic data and we simplified the fault network, keeping only 11 growth faults. Wells penetrated the section only down to $4.6 \mathrm{~km}$, therefore deeper-level deposits were inferred from the seismic facies whenever possible, or from a purely conceptual interpretation. As the number of restoration steps required equals the number of deposition events, it was too timeconsuming to increase the stratigraphic resolution up to typical deltaic sequence thicknesses. The model lithology is therefore upscaled, keeping only the main features of the section (Fig. 3). The case has many shaly layers of different types, among which the shaly MFS layers (Maximum Flooding Surface) act as vertical seals (confidential data). Fault locations are shown in Figure 4.

The basement is a no-flow boundary. We implemented this hypothesis in the model by imposing porosity $=0 \%$ and pore pressure $=$ hydrostatic pressure for the three basement layers in all the simulations described in the next sections. 
S

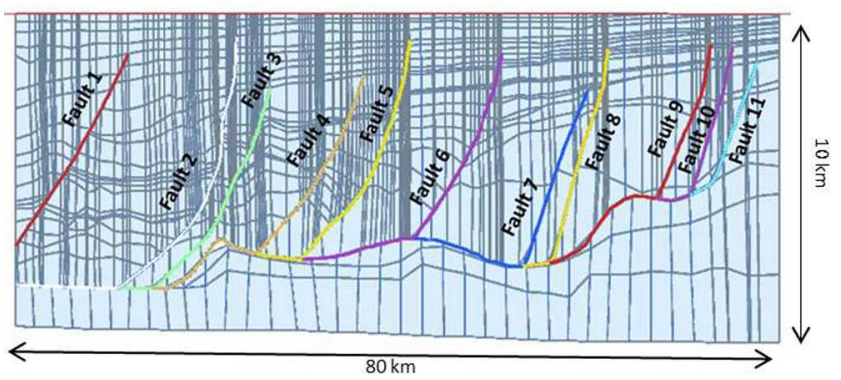

Figure 4

Fault locations. Each individual fault is identified with a different color.

\subsection{First Simulations}

To assess the impact of fault properties on pressure at presentday, we first performed two simulations with an "extreme" fault configuration: one with impervious faults all along the geological history and another with transparent faults, i.e. fault zones impact fluid flow only through the layer juxtaposition across the fault. In the latter case, fault core and damage zone share the permeability of the hostrock.

Overpressure results at the end of the runs are shown in Figure 5. When faults do not act as permeability barriers (Fig. 5a) and allow across-fault connection between permeable layers, no overpressures are simulated on the section at the end of the simulation, except in the thickest layers of Shaly MFS (overpressure $\sim 10 \mathrm{MPa}$ ). On the contrary, impervious faults (Fig. 5b) lead to strong overpressures at the end of the simulation, up to $51 \mathrm{MPa}$ in the deepest layers. The different over-pressured zones are limited by the faults and the Shaly MFS layers, which act as vertical barrier to fluid flow because of their very low vertical permeability. These runs show that faults play a major role for overpressure building on the section: faults must be barrier to fluid flow for overpressure to increase to high values. Petroleum generation and migration are disregarded in our simulations, and a connection between overpressure and petroleum saturation is of course possible but only as an additive process. Since the main driver of overpressures is compaction disequilibrium, if a section is well drained no other mechanism could generate significant overpressures.

Six wells with pressure data cross the section (Fig. 3). Only the four central wells reach the top of overpressure, between $3000 \mathrm{~m}$ and $4000 \mathrm{~m}$ depth (see Fig. 6). For the simulation with impervious faults pressure results at the location and depths of well 1 and well 6 are close to hydrostatic values, in agreement with data. For well 5, the simulation fails to reproduce the pressure increase around $3500 \mathrm{~m}$ depth. Impervious faults allow to simulate overpressures at wells 2, 3 and 4, but datamodel comparison displays only a moderate agreement. The pressure decrease simulated at well 5 at $4000 \mathrm{~m}$ depth corresponds to the crossing of fault 5 (see Fig. 3). a) Transparent faults

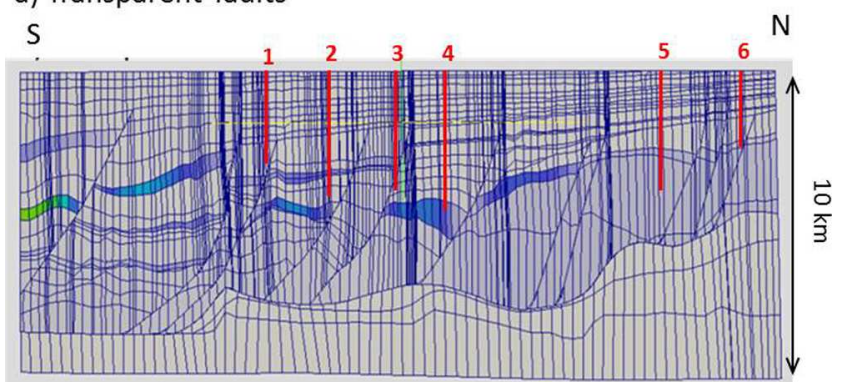

b) Impervious faults

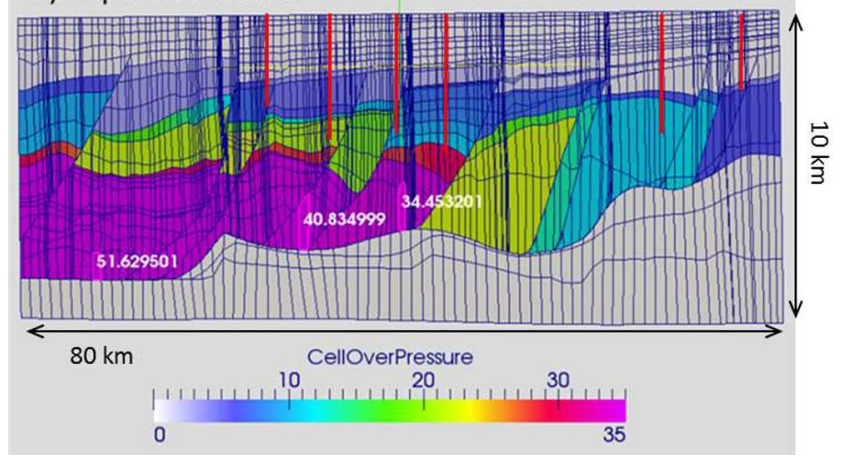

Figure 5

Overpressure (MPa) at the end of the simulation in the case of (a) transparent faults and (b) impervious faults. Vertical red lines indicate the location of the six wells.

One of the main reasons explaining the discrepancy is the lack of vertical stratigraphic resolution in our model, especially for the well 5 which crosses a very thick layer of "Shaly Shelf" in our model (more than $2 \mathrm{~km}$ ) which actually corresponds to thinner interbedded sand and shale layers. The pressure profile is strongly controlled by the thickness and location of the shaly MFS layers, which in our model are thicker and less numerous than observed at the wells. Therefore, we cannot expect a perfect match between pressure data and simulation results. These sensitivity tests merely show that faults acting as barrier to fluid flow are crucial to compartmentalize the section and to explain the strong overpressure building in the system. However, a scenario with impervious faults is not satisfactory. Faults also have to be efficient drains to explain petroleum migration from the deep source rocks to the shallow reservoirs. In other words, fault properties cannot be constant throughout the simulation but have to evolve through time to allow both drain and barrier behaviours during basin history.

\section{IMPROVING FAULT MODELLING}

The way faults are handled in the calculator allows the user to build complex scenarios of faults behaviour through time by playing with the thickness and permeability values in the fault core and the damage zone cells (see Sect. 1). However, defining the appropriate values and their evolution and 


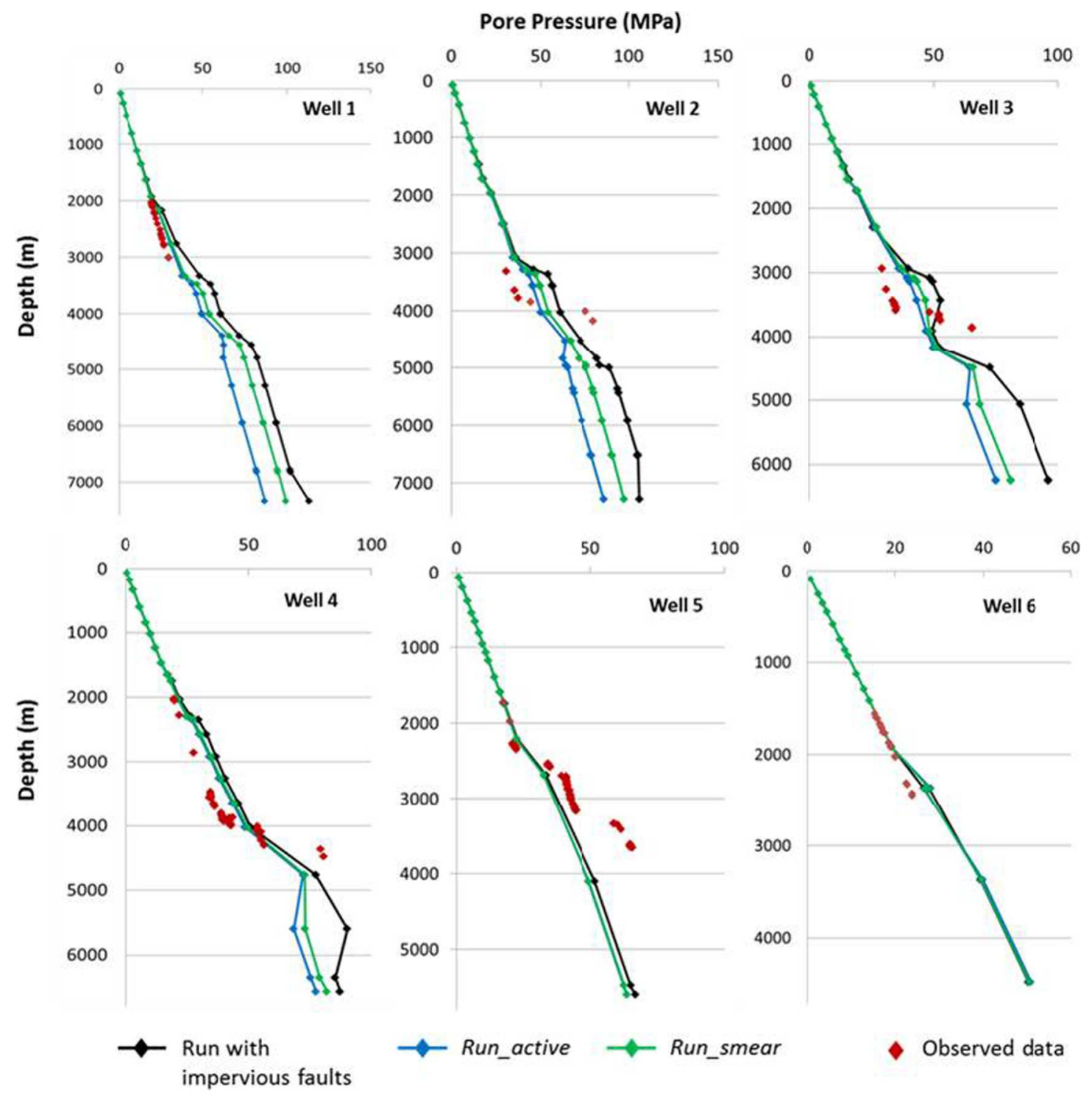

Figure 6

Pressure data from wells (red) and pressure results for a simulation with impervious faults (black) and for the simulation Run_smear and Run active (green and blue respectively, see Sect. 3.3 for the fault properties). See Figure 3 for wells location on the section.

implementing them manually in the calculator, which is the classical method in basin modelling, is a complex and timeconsuming task. Therefore, an automatic method to predict fault properties through time and spare this step in the building of the scenario would be very useful to the user. Such a method has been proposed for instance by Kacewicz et al. (2008). Here we present a new numerical tool developed for ArcTem to compute fault properties through time as a function of available geological parameters.

\subsection{Fault Core Properties}

Classically, in this geological context, the permeability of the fault core is determined via empirical relationships with the Shale Gouge Ratio (SGR) (Manzocchi et al., 1999;
Sperrevik et al., 2002). The SGR is a way to quantify the amount of shale or clay that might be smeared in the fault zone during fault slip. The more shaly the host rock is, the greater the proportion of shale in the fault zone. It is a way to measure the contact through time of a given sedimentary layer with layers with different shale content. For multiple layers it is defined as follows:

$$
\mathrm{SGR}=\frac{\sum\left(V_{\mathrm{sh}} \cdot \Delta z\right)}{\text { throw }} \times 100 \%,
$$

with $V_{\text {sh }}$ the shale content (phyllosilicates) of a layer and $\Delta z$ the layer thickness.

However, the use of the SGR is based on the hypothesis that the fault core is composed of a homogeneous mixture of material coming from the host rocks. This assumption is not 
TABLE 1

Shale content of the different lithologies used on the ArcTem section (see Fig. 3). We assume that the shale fraction is mainly composed of phyllosilicates.

\begin{tabular}{l|c}
\hline Lithology & Shale content \\
\hline Benin sandstone & 0 \\
\hline Shaly MFS & 0.98 \\
\hline Shaly Slope & 0.98 \\
\hline Sandy shelf & 0.5 \\
\hline Shaly shelf & 0.5 \\
\hline Sandy transitional & 0.09 \\
\hline Sandy slope & 0.01 \\
\hline Mobile shale & 0.7 \\
\hline Cretaceouscarb & 0.01 \\
\hline Cretaceous carbshale & 0.7 \\
\hline Paleocene & 0.98 \\
\hline
\end{tabular}

always valid and two main other possibilities have to be considered: the formation of a continuous shale smear and the fracturing of the fault core in case of previous overconsolidation or cementation. Some studies suggest that for SGR $>40-50 \%$ the fault rock is dominated by shale smears (Yielding et al., 2010). Above this threshold, the trapping potential of the fault does not seem to depend on the SGR value anymore. It seems that around $40-50 \%$ the sealing by clay smears becomes complete and is not further enhanced for higher shale content. To simulate at the first order the impact of these different fault core types, we will follow the classical approach and compute the fault core cell permeability as a function of the SGR, but we will also include a specific behaviour when the SGR reaches a critical threshold value.

In order to assess the fault core permeability, SGR values along the fault plane at each timestep are now computed in ArcTem as a function of the lithology's shale content and the displacement length on the fault. The lithology shale/clay content is an input variable the user has to define in the calculator before launching a simulation. For our section, we used the values summarized in Table 1. A shale content of $50 \%$ was allocated to the "sandy shelf" and "shaly shelf" lithologies since the cells filled with one of these lithologies correspond actually to interbedded sand and shale layers at higher vertical stratigraphic resolution. This choice aims at computing SGR values in the fault parts crossing these layers more in agreement with the real geological setting.

The SGR computed by ArcTem is then used as a first order-predicting factor to compute the fault core permeability through time. We define two SGR threshold values
$\mathrm{SGR}_{\min }$ and $\mathrm{SGR}_{\max }$, with default values of $15 \%$ and $50 \%$, respectively. These default values may be freely changed by the user. Three different cases are considered:

- $\mathbf{S G R}<\mathbf{S G R}_{\text {min }}$ : The fault core has a high sand content and is considered to be an homogeneous mixture of material coming from the hostrocks. If the temperature is below $90{ }^{\circ} \mathrm{C}$, the fault core permeability Kac is computed as a function of the SGR and effective stress, following an in-house equation whose parameters can be adapted by the user. If the temperature is above $90^{\circ} \mathrm{C}$, we assume that quartz cementation has occurred. Fault core fracturing is assumed during fault slip and permeability is increased to a high user-defined value. When the fault is no longer active, Kac is set to a low user-defined value to account for permeability reduction with quartz cementation.

$-\mathbf{S G R}_{\min }<\mathbf{S G R}<\mathbf{S G R}_{\text {max }}$ : The fault core has an intermediate shale content and is considered to be a homogeneous mixture of material coming from the hostrocks. Kac is computed as a function of the SGR and effective stress.

- SGR $>$ SGR $_{\text {max }}$ : We assume the presence of a shale smear, Kac value is set to a low user-defined value so that the fault core strongly reduces across-fault fluid flow.

The results of the SGR calculation for present-day are shown in Figure 7. Given the high shale content of the lithologies filling the section (see Tab. 1), the SGR values are above the default threshold value for shale smear (SGR $>0.5$ ) over most parts of the faults. Therefore, the fault cores are expected to have a very low permeability and to be a barrier to across-fault fluid flow.

The thickness of the fault core also has to be defined (Fig. 1). Natural fault zones can combine many different internal structures in the core (Evans, 1990; Shipton et al., 2006; Faulkner et al., 2008), yet the analysis of different fault core thicknesses shows a similar behaviour, and a positive relationship between fault core thickness and fault throw can be defined in a log-log plot (Torabi and Berg, 2011). Therefore, a power law seems to be the best to compute fault core thickness as a function of fault throw. We chose to compute the fault core cells thickness in ArcTem as $E c=a T^{b}$, with $T$ the fault throw in meters and $a$ and $b$ two constants that can be chosen by the user. By default $a=0.02$ and $b=0.5$, following the average relationship for sandstones (and carbonates) of Schueller et al. (2013). With these parameters, the fault core thickness is less than $2 \mathrm{~m}$ for all faults on the section at the end of the run. Thus, we can expect that very low values of Kac will be necessary for the fault core to have a significant impact on across-fault water flow.

We performed several pressure simulations with different values of Kac in the case of a shale smear to assess the acrossfault permeability required to build overpressure on the 


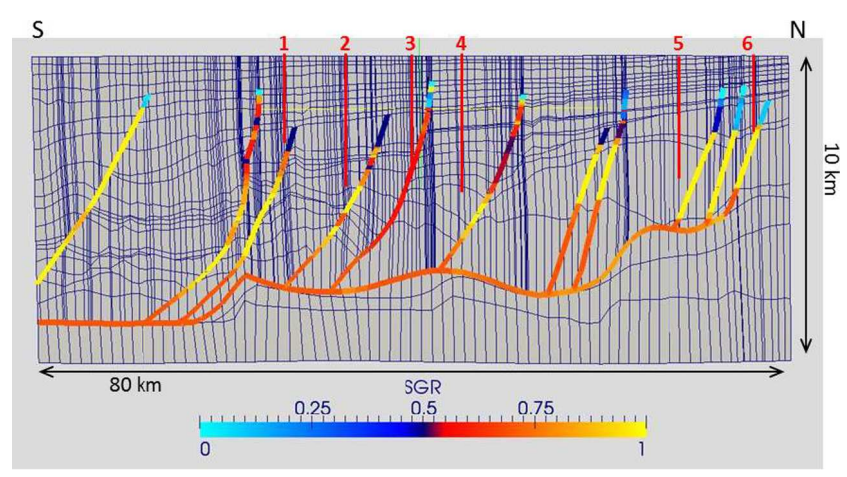

Figure 7

SGR values along the fault planes at the end of the simulation. Vertical red lines indicate the location of the six wells.

section. Results have shown that overpressures are simulated at present-day for Kac values lower than $1 \mathrm{nD}$. Figure 8 shows the overpressure simulated for present-day when $\mathrm{Kac}=0.1 \mathrm{nD}$ (simulation hereafter labelled Run_smear). Different overpressured zones have been built, limited laterally by the faults and vertically by the shaly MFS layers. The threshold permeability to simulate overpressure of course depends on fault core thickness, and we could obtain the same results with a higher Kac value but a thicker fault core. Indeed, for faults with a throw of several hundreds of meters the area identified as a fault zone on a seismic profile is not a single fault but rather a cluster of several faults, i.e. a complex structure with several stacked fault cores. However, $\mathrm{Kac}=0.1 \mathrm{nD}$ is not unrealistic compared to published permeability values for shales at minimum porosity $(0.1 \mathrm{nD}$ at phi $=5 \%$, Yang and Aplin, 2010).

The developments to compute the fault core permeability give satisfactory results and leads to over-pressure building and compartmentalization of the section. For the deep layers (burial depth $>4000-5000 \mathrm{~m}$ ) the overpressures simulated in Run_smear are lower by $\sim 10$ to $20 \mathrm{MPa}$ than in the simulation with completely impervious faults (Fig. 5a vs. Fig. 8). However, at these depths we have no pressure data to compare with. The pressure profiles at well locations for Run_smear or for the impervious fault simulation (Fig. 6) are similar for the first $4000 \mathrm{~m}$, i.e. still within the observed pressure data range, except for well 5. Thus, the developments to compute the fault core permeability give satisfactory results and allow one to model overpressure build up in the section.

\subsection{Damage Zone Properties}

Faults must have a role in petroleum migration from the deep shales to the shallow reservoirs of the section. Considering the lithologies involved in faulting, along-fault migration could be necessary, even if the impact of sedimentary heterogeneity, multiphase flow fault properties and the 3D connectivity

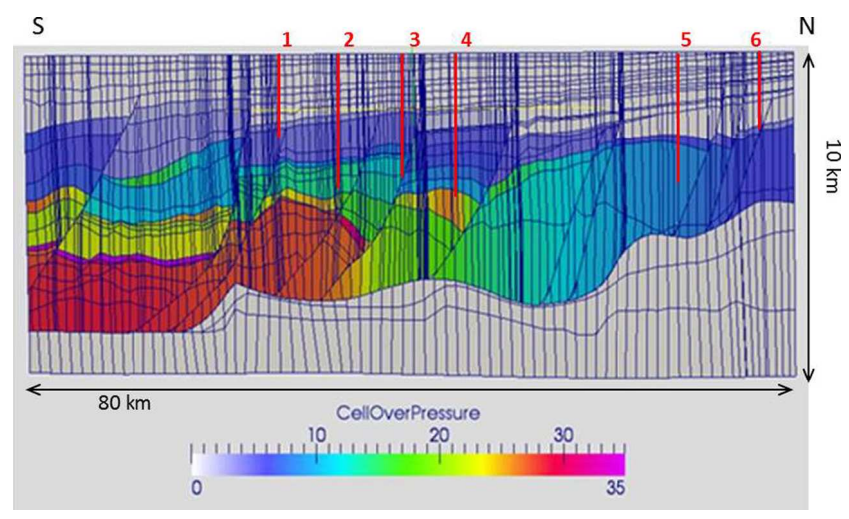

Figure 8

Overpressure (MPa) simulated at present-day with ArcTem when the fault core permeability Kac is computed as a function of the SGR, with $\mathrm{Kac}=0.1 \mathrm{nD}$ when $\mathrm{SGR}>50 \%$ (shale smear). Vertical red lines indicate the location of the six wells.

effects cannot be ruled out. All lithologies except the Benin sandstones have a shale content above $50 \%$ (Tab. 1). In this case the deformation in the damage zone is accommodated through multiple faults with clay smearing leading to a decrease of across permeability and not through fracturing, which could create a longitudinal drain for fluid flow. A model of transient flow through shale-rich lithologies during fault activation could be considered, as discussed by Revil and Cathles (2002) and Wilkins and Naruk (2007) in the Gulf of Mexico. To improve fault modelling in ArcTem, we thus chose to follow the classical view of an increase of the longitudinal fault permeability during fault slip.

Since ArcTem simulates realistic fault kinematics with layer displacements along a fault plane we can now compute the fault displacement velocity $V_{\text {fault }}$ in the calculator and use it to define the periods of fault activity and to automatically compute the permeability increase during a simulation. We chose a threshold of $50 \mathrm{~m} / \mathrm{Ma}$, a classical value used to define fault activity in basin modelling (IFPEN internal confidential note). When $V_{\text {fault }}>50 \mathrm{~m} / \mathrm{Ma}$, we consider that the damage zone is a preferential pathway for fluid flow and allows a quasiinstantaneous fluid migration along the fault at the time-scale of a basin simulation. The longitudinal damage zone permeability is computed as

$$
\mathrm{Kl}=K_{0} \cdot \exp \left(-P_{\text {eff }} / a\right),
$$

with $K_{0}$ a high value (by default $1 \mathrm{mD}$ ), $P_{\text {eff }}$ the effective stress and $a$ a constant.

This formula accounts for the sensitivity of the damage zone permeability to effective stress, as shown by Lockner et al. (2009) for non-sedimentary rocks (granodiorites of the Nojima fault, Japan). Even if the protolith is different here, we assume that the deformation mechanisms are similar, with the opening of fractures and cracks in the damage zone, and therefore that sedimentary rocks should 


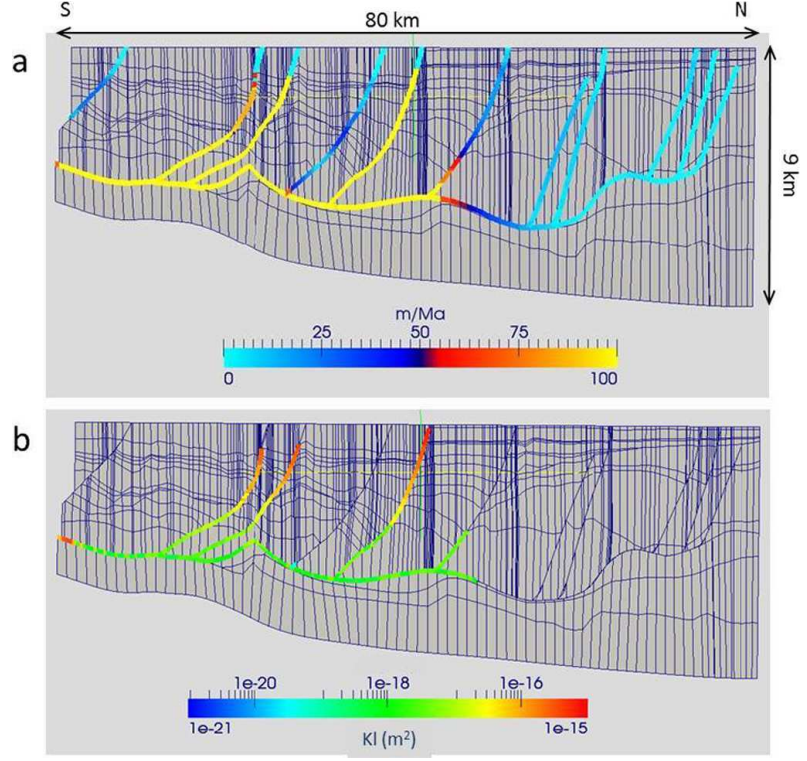

Figure 9

(a) Mean fault displacement velocity $(\mathrm{m} / \mathrm{Ma})$ during the event -20.2 to $-17.9 \mathrm{Ma}$. The red to yellow zones have velocity above $50 \mathrm{~m} / \mathrm{Ma}$ (=active fault). (b) Longitudinal permeability (K1) in the damage zone cells (in $\mathrm{m}^{2}$ ) during the same event on active fault parts only.

also show a sensitivity to the effective stress. The default value set for $a$ is $10.5 \mathrm{MPa}$. When the fault is no longer active $\left(V_{\text {fault }}<50 \mathrm{~m} / \mathrm{Ma}\right)$, the longitudinal permeability equals the permeability of the hostrock (a combination of the strata and anti-strata hostrock permeability, depending on the fault angle). The across permeability does not change with fault activity and remains equal to the hostrock permeability. Since we simply want to simulate an efficient longitudinal drain, a realistic damage zone thickness is not required, different Kl-Edz pairs are possible for the same results and should be calibrated for a real case study. By default, $\mathrm{Edz}=\mathrm{aT}^{\mathrm{b}}$ for $T<5000 \mathrm{~m}$ and $\mathrm{Edz}=70 \mathrm{~m}$ for $T>5000 \mathrm{~m}$, with $T$ the fault throw in meters and $a=1$ and $b=0.5$ (Schueller et al., 2013).

Using this approach fault permeability changes only on the parts of the fault plane actually slipping and not on the whole fault length (Fig. 9a). The corresponding Kl values are shown in Figure 9b. For the event illustrated in Figure 9, Kl values on active fault parts range between $1 \mathrm{mD}$ and $0.1 \mu \mathrm{D}$, which is still a rather high permeability value at the basin time scale. For each event, we visually identify on the calculator outputs the faults with $V_{\text {fault }}>50 \mathrm{~m} / \mathrm{Ma}$. The periods of fault activity obtained in this way are synthesized in Table 2 .

For the faults 2 to 6 , the fault activity periods occur between $34.2 \mathrm{Ma}$ and $15 \mathrm{Ma}$. Faults 7 to 10 are active only before $26 \mathrm{Ma}$ and only during relatively short time-scale of one or two events. No activity period is identified for fault
11 , which is not surprising given its very small displacement ( $\sim 40 \mathrm{~m}$ at present-day). The most recent activity period is identified for fault 1 , between 24.8 and $9.54 \mathrm{Ma}$.

\subsection{Pressure Results}

A new pressure simulation (hereafter labeled Run_active) is performed with increasing longitudinal damage zone permeability $(\mathrm{Kl})$ during periods of fault activity, as described in the previous section. The fault core permeability is computed similarly to Run_smear. Over-pressure evolution is shown in Figure $10 \mathrm{~b}$ and compared with the results obtained when only the fault core permeability changes are taken into account (Run_smear, Fig. 10a).

Contrary to Run_smear, where overpressure building starts at $-17 \mathrm{Ma}$, in Run_active the longitudinal drainage simulated along active fault parts prevents overpressure building. Overpressure starts to increase only once $\mathrm{Kl}$ has been set back to the hostrock permeability value. In the deep layers in the south part of the section, fault 2 is an efficient drain until $-9.54 \mathrm{Ma}$ (Tab. 2) and overpressures in this zone are built in the last Ma of the simulation. Due to efficient drainage along the faults in the past, overpressures simulated at the end of Run_active are lower than in Run_smear by about $10 \mathrm{MPa}$ in the deepest layers, but nonetheless reach $\sim 20 \mathrm{MPa}$ in the deep layers. However, since the pressure data from the wells only show the top of the over pressured zones, we cannot assess the relevance of our model for the overpressure modelling at depths beyond $4000 \mathrm{~m}$. The pressure profiles at well locations are similar to the profiles obtained with Run_smear or the impervious faults (Fig. 6).

Thus, the modelled fault properties allow the simulation of both along-fault drainage during basin history as well as overpressure at present-day, as long as faults are strong permeability barriers in the last events of the simulation.

\section{CONCLUSION}

We have used the basin calculator ArcTem (TemisFlow software) developed at IFPEN to perform 2D simulations in a complex geological setting and to improve fault modelling. The area chosen for this study is a 2D crosssection located in the onshore area of the Niger Delta. The sedimentary layers are crossed by several growth faults which are thought to play a crucial role in over-pressure building and petroleum migration. A simplified section with 24 layers and 11 normal faults was successfully restored and meshed and several ArcTem pressure simulations were performed for different fault config- 
TABLE 2

Grey cells: periods of fault activity simulated with the new ArcTem calculator. Fault activity is defined as $V_{\text {fault }}>50 \mathrm{~m} / \mathrm{Ma}$ over a significant part of the fault plane.

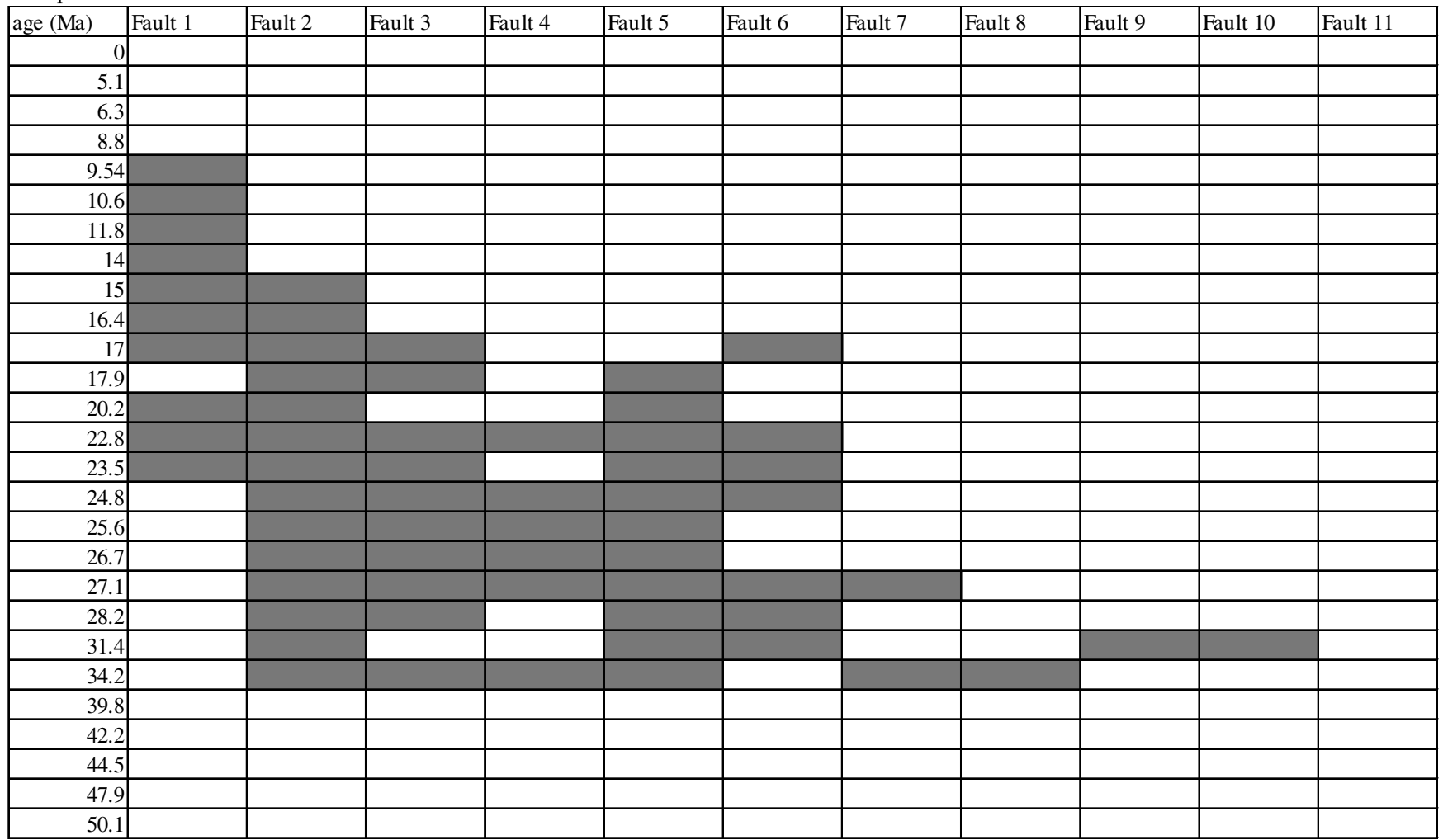

urations. All the simulations run to the end, even with abrupt fault permeability changes, showing the improved stability of the calculator compared to classic basin calculator where fault modelling is often a source of numerical instabilities.

A new numerical tool was developed to automatically compute fault core and damage zone properties in ArcTem during a simulation, as a function of available geological parameters. Given the complexity of the different features that can be encountered in fault areas, and the fact that the properties on one section should integrate $3 \mathrm{D}$ behaviour, we built a flexible tool with adjustable parameters that can be adapted by the user. The SGR is now automatically computed in ArcTem, as a function of the fault throw and shale content of the hostrocks, and used as an input variable to compute the fault core permeability. For high SGR values (default $>50 \%$ ), we assumed the presence of a shale smear and the fault core permeability is set to a very low value. For our section, this is the case for most fault parts because of the high shale content of the hostrocks. We also used the fault displacement velocity to compute the periods of fault activity and increase automatically the longitudinal permeability on the damage zone, thus creating longitudinal drains. The computed fault activity periods compare well with the periods of fault opening which had been tuned manually in a previous confidential study to allow petroleum migration.

The method allows us to simulate both along-fault drainage during the basin history as well as overpressure at present-day. The over-pressure simulated at present-day is in range with observed wells data, except for one well, where the final ramp could not be reproduced. The datamodel discrepancy for the last well data is partly due to the 2D approach and the coarse stratigraphic resolution. It will be interesting to test again our methodology on a new section with an improved stratigraphic resolution to allow more quantitative model-data comparison. In any case matching pressure data on this section is a known challenge even with an improved stratigraphic resolution. Overpressure transfer from deep layers to the shallower reservoirs has been proposed as a plausible mechanism to explain the high overpressure values recorded at the wells. Such process requires first over-pressure building in the deep layers, and our simulations have shown it can occur only after fault closure. Overpressure transfer along the faults from the deep layers to the shallowest layers after the end of fault activity period means that faults should have been re-activated during the last simulation events. 
$a$

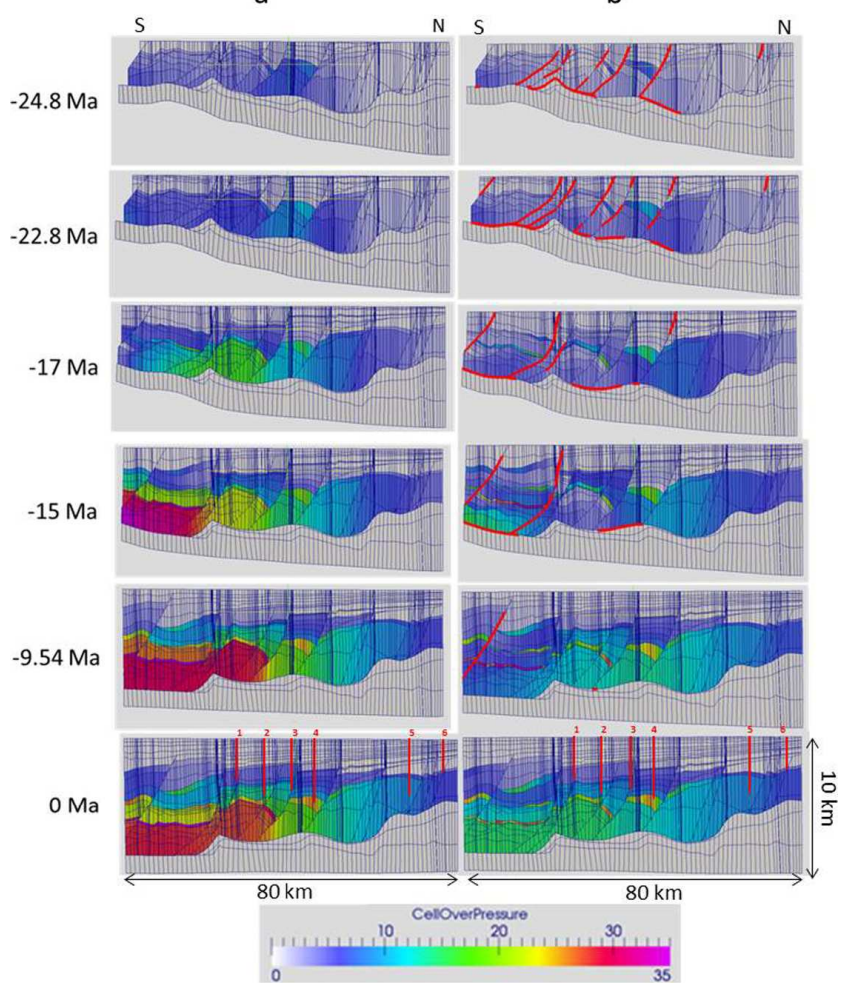

Figure 10

Overpressure (MPa) simulated when (a) the fault core permeability is computed as a function of the SGR, with $\mathrm{Kac}=0.1 \mathrm{nD}$ when $\mathrm{SGR}>50 \%$; (b) the fault core permeability is computed as a function of the SGR, with $\mathrm{Kac}=0.1 \mathrm{nD}$ when SGR $>50 \%$ and the damage zone longitudinal permeability during fault activity is computed as $\mathrm{Kl}=K_{0} \cdot \exp \left(-P_{\text {eff }} / 10.5\right)$ with $K_{0}=1 \mathrm{mD}$ a high value, and $P_{\text {eff }}$ the effective stress (MPa) A fault is active when the mean displacement velocity $V_{\text {fault }}>50 \mathrm{~m} / \mathrm{Ma}$. Active fault parts are highlighted in red on the section. Vertical red lines indicate the location of the six wells at present-day.

This could result from natural hydraulic fracturing in response to over-pressure increase through compaction processes or because of petroleum accumulation along impervious fault planes. Changes in the lateral effective stress could also play a role, but only the vertical effective stress is taken into account in the current ArcTem version. Further developments in ArcTem are required to investigate these hypotheses.

\section{ACKNOWLEDGMENTS}

The authors would like to thank Renaud Divies (IFPEN) for his restoration of the model. This work has been carried out within the framework of a scientific partnership between IFPEN and Total (Cornu et al., 2016).

\section{REFERENCES}

Aydin A. (1977) Faulting in sandstone, PhD Thesis, Stanford University, Stanford, California, $282 \mathrm{p}$.

Aydin A. (1978) Small faults formed as deformation bands in sandstone, Pure Appl. Geophys. 116, 913-930.

Caillet G., Batiot, S. (2003) 2D modeling of hydrocarbon migration along and across growth faults: an example from Nigeria, Petrol Geosci 9, 113-124.

Caine J.S., Evans J.P., Forster C.B. (1996) Fault zone architecture and permeability structure, Geology 24, 1025-1028.

Childs C., Walsh J.J., Manzocchi T., Strand J., Nicol A., Tomasso M., Schöpfer M.P.J., Aplin A.C. (2007) Definition of a fault permeability predictor from outcrop studies of a faulted turbidite sequence, Taranaki, New Zealand, in: Jolley S.J., Barr D., Walsh J.J., Knipe R.J. (eds), Structurally complex reservoirs, Geol. Soc. Lond. Spec. Publ. 292, 235-258.

Cornu T., Gout C., Cacas-Stenz M.-C., Woillez M.-N., Guy N., Bouziat A., Colombo D., Frey, J. (2016) NOMBA an integrated project for coupling basin modeling and geomechanical simulations, in: AAPG Hedberg conference: the future of basin and petroleum system modeling, April 2016.

Evans J.P. (1990) Thickness displacement relationships for fault zones, J. Struc. Geol. 12, 8, 1061-1065.

Faille I., Thibaut M., Cacas M.-C., Havé P., Willien F., Wolf S., Agelas L., Pegaz-Fiornet S. (2014) Modeling fluid flow in faulted basins, Oil Gas Sci. Technol. - Rev. IFP 69, 4, 529-553.

Faulkner D.R., Mitchell T.M., Rutter E.H., Cembrano J. (2008) On the structure and mechanical properties of large strike-slip faults, Geol. Soc. Lond. Spec. Publ. 299, 1, 139-150.

Fisher Q.J., Casey M., Harris S.D., Knipe R.J. (2003) Fluid-flow properties of faults in sandstone: the importance of temperature history, Geology 31, 11, 965-968.

Fredman N., Tveranger J., Semshaug S., Braathen A., Sverdrup E. (2007) Sensitivity of fluid flow to fault core architecture and petrophysical properties of fault rocks in siliciclastic reservoirs: a synthetic fault model study, Petrol. Geosci. 13, 4, 305-320.

Grauls D.J., Baleix J.M. (1994) Role of overpressures and in situ stresses in fault-controlled hydrocarbon migration: a case study, Mar. Petrol. Geol., 11, 6, 734-742.

Kacewicz M., Davies R.K., Welch M., Knipe R.J. (2008) An integration of fault rock properties through time with basin modeling, Search Discov, Article \#40349.

Lander R.H., Larese R.E., Bonnell L.M. (2008) Toward more accurate quartz cement models: the importance of euhedral versus non-euhedral growth rates, $A A P G$ Bull. 92, 11, $1537-1563$

Lander R.H., Walderhaug O. (1999) Porosity prediction through simulation of sandstone compaction and quartz cementation, Am. Assoc. Petrol. Geol. Bull., 83, 433-449.

Lockner D.A., Tanaka H., Ito H., Ikeda R., Omura K., Naka H. (2009) Geometry of the Nojima fault at Nojima-Hirabayashi, Japan - I. A simple damage structure inferred from borehole core permeability, Pure Appl. Geophys., 166, 1649-1667.

Manzocchi T., Walsh J.J., Nell P., Yielding G. (1999) Fault transmissibility multipliers for flow simulation models, Petrol. Geosci., 5, 1, 53-63.

Manzocchi T., Childs C., Walsh J.J. (2010) Faults and fault properties in hydrocarbon flow models, Geofluids, 10, 1-2, 94-113. 
Micarelli L., Benedicto A., Wibberley C.A.J. (2006) Structural evolution and permeability of normal fault zones in highly porous carbonate rocks, J. Struct. Geol., 28, 7, 1214-1227.

Mitchell T.M., Faulkner D.R. (2012) Towards quantifying the matrix permeability of fault damage zones in low porosity rocks, Earth Planet. Sci. Lett., 339, 24-31.

Peters K.E., Magoon L.B., Lampe C., Scheirer A.H., Lillis P.G., Gautier D.L. (2008) A four-dimensional petroleum systems model for the San Joaquin Basin Province, California: Chapter 12 in Petroleum systems and geologic assessment of oil and gas in the San Joaquin Basin Province, California (No. 1713-12). US Geological Survey.

Revil A., Cathles L.M. (2002) Fluid transport by solitary waves along growing faults: a field example from the South Eugene Island Basin, Gulf of Mexico, Earth Planet. Sci. Lett. 202, 2, 321-335.

Rudkiewicz J.L., Penteado H.D.B., Vear A., Vandenbroucke M., Brigaud F., Wendebourg J., Duppenbecker S. (2000) Chapter 3: Integrated Basin Modeling Helps to Decipher Petroleum Systems, in: AAPG Memoir 73.

Schmatz J., Vrolijk P.J., Urai J.L. (2010) Clay smear in normal fault zones - the effect of multilayers and clay cementation in watersaturated model experiments, J. Struct. Geol. 32, 11, 1834-1849.

Schueller S., Braathen A., Fossen H., Tveranger J. (2013) Spatial distribution of deformation bands in damage zones of extensional faults in porous sandstones: statistical analysis of field data, J. Struct. Geol. 52, 148-162.

Shipton Z.K., Soden A.M., Kirkpatrick J.D. (2006) How thick is a fault? Fault displacement-thickness scaling revisited, in: Earthquakes: radiating energy and the physics of faulting, Geophys. Mon. 170, 193-198.

Schneider S., Wolf S., Faille I., Pot D. (2000) A 3D basin model for hydrocarbon potential evaluation: application to Congo offshore, Oil Gas Sci. Technol. - Rev. IFP 55, 1, 3-13.
Sperrevik S., Færseth R.B., Gabrielsen R.H. (2000) Experiments on clay smear formation along faults, Petrol. Geosci. 6, 2 , 113-123.

Sperrevik S., Gillespie P.A., Fisher Q.J., Halvorsen T., Knipe R.J. (2002) Empirical estimation of fault rock properties, Nor. Petrol. Soc. Spec. Publ. 11, 109-125.

Torabi A., Berg S.S. (2011) Scaling of fault attributes: a review, Mar. Petrol. Geol. 28, 1444-1460.

Tunc X., Faille I., Gallouët T., Cacas M.-C., Havé P. (2012) A model for conductive faults with non-matching grids, Comput. Geosci. 16, 2, 277-296, doi:10.1007/s10596-011-9267-x.

Vidale J.E., Li Y.G. (2003) Damage to the shallow Landers fault from the nearby Hector Mine earthquake, Nature 421, 6922, 524-526.

Walderhaug O. (1996) Kinetic modeling of quartz cementation and porosity loss in deeply buried sandstone reservoirs, Am. Assoc. Petrol. Geol. Bull. 80, 731-745.

Wibberley C.A., Yielding G., Di Toro G. (2008) Recent advances in the understanding of fault zone internal structure: a review, Geol. Soc. London, Spec. Publ. 299, 1, 5-33.

Wibberley C.A., Gonzalez-Dunia J., Billon O. (2016) Faults as barriers or channels to production-related flow: insights from case studies, Petrol. Geosci., petgeo 2016-057.

Wilkins S.J., Naruk S.J. (2007) Quantitative analysis of slipinduced dilation with application to fault seal, AAPG Bull. 91, 1, 97-113.

Yang Y., Aplin A.C. (2010) A permeability-porosity relationship for mudstones, Mar. Petrol. Geol. 27, 8, 1692-1697.

Yielding G., Bretan, P., Freeman, B. (2010) Fault seal calibration: a brief review, Geol. Soc. Lond. Spec. Publ. 347, 243-255.

Manuscript submitted in 20 February 2017 Manuscript accepted in 22 August 2017

Published online in October 2017 